\title{
Availability of snacks, candy and beverages in hospital, community clinic and commercial pharmacies
}

\author{
Anne Whitehouse ${ }^{1}$, Anna Simon ${ }^{1}$, Simone A French ${ }^{1, *}$ and Julian Wolfson ${ }^{2}$ \\ 'Division of Epidemiology \& Community Health, University of Minnesota, 1300 South 2nd Street \#300, \\ Minneapolis, MN 55454, USA: ${ }^{2}$ Division of Biostatistics, University of Minnesota, Minneapolis, MN, USA
}

Submitted 25 August 2011: Accepted 8 December 2011: First published online 25 January 2012

\begin{abstract}
Objective: The purpose of the present study was to measure the availability of energy-dense foods and sugar-sweetened beverages in pharmacies and to examine differences by pharmacy type and presence of a food policy.

Design: Trained research staff visited pharmacies ( $n$ 37) to measure shelf space and variety of snacks, candy and sugar-sweetened beverages available within $10 \mathrm{ft}$ $(3.05 \mathrm{~m})$ of the pharmacy register.

Setting: Community clinic, hospital and commercial pharmacies in Minneapolis, MN, USA.

Subjects: Employees were interviewed regarding pharmacy food policies.

Results: Approximately $60 \%$ of pharmacies had foods and/or sugar-sweetened beverages available for purchase within $10 \mathrm{ft}(3.05 \mathrm{~m})$ of the pharmacy register. Total shelf space $(P=0 \cdot 02)$ and variety $(P=0.0003)$ differed significantly by pharmacy type and were greatest among community clinic pharmacies. Over half of pharmacies had no food policy (58.3\%). Pharmacies with food policies were less likely to have foods/beverages available within $10 \mathrm{ft}(3.05 \mathrm{~m})$ of the pharmacy register than pharmacies with no food policies $(P=0 \cdot 03)$.

Conclusions: Candy, snacks and sugar-sweetened beverages are highly available in the pharmacy environment. Presence of a policy is associated with less food availability within $10 \mathrm{ft}(3.05 \mathrm{~m})$ of the pharmacy register and represents an important potential intervention strategy.
\end{abstract}

\author{
Keywords \\ Pharmacy \\ Food environment \\ Sugar-sweetened beverages
}

The availability of salty snacks, candy and sweetened beverages in the USA has increased over the past few decades $^{(1)}$ and may be a prominent contributor to the rising consumption of energy-dense foods and the coinciding obesity epidemic ${ }^{(2)}$. Although data are limited, energy-dense foods are available in many retail environments that do not specialize in food sales ${ }^{(3)}$. In one study, energy-dense foods including salty snacks, candy and sweetened beverages were available for purchase in $41 \%$ of primarily non-food stores ${ }^{(3)}$. Compared with other types of primarily non-food stores, pharmacies were highly likely to offer energy-dense foods, with $96 \%$ of pharmacies offering snack foods, $90 \%$ offering candy and $89 \%$ offering sweetened beverages ${ }^{(3)}$.

The high proportion of pharmacies offering snacks, candy and sweetened beverages is particularly disturbing, given that pharmacies are health-promoting environments. The availability of energy-dense snacks, candy and sweetened beverages counteracts this health promotion function by providing customers with an opportunity to purchase and consume the same energy-dense foods that may be contributing to their illnesses.
To better understand the food environment in pharmacies and how it may be contributing to the high consumption of energy-dense foods, data describing the availability of candy, snacks and sugar-sweetened beverages in pharmacies are needed. The purpose of the present study was to describe the availability of foods, including snacks, candy and beverages, in commercial, community clinic and hospital pharmacies and to determine if the availability of these foods and beverages differs by pharmacy type or the presence of a food policy.

\section{Experimental methods}

\section{Study overview}

Pharmacy identification, inclusion criteria and sample selection

Pharmacies in Minneapolis, MN, USA were surveyed between November 2010 and January 2011. The study received approval from the Institutional Review Board for the University of Minnesota-Twin Cities. The pharmacy sample identification, screening and final inclusion are 


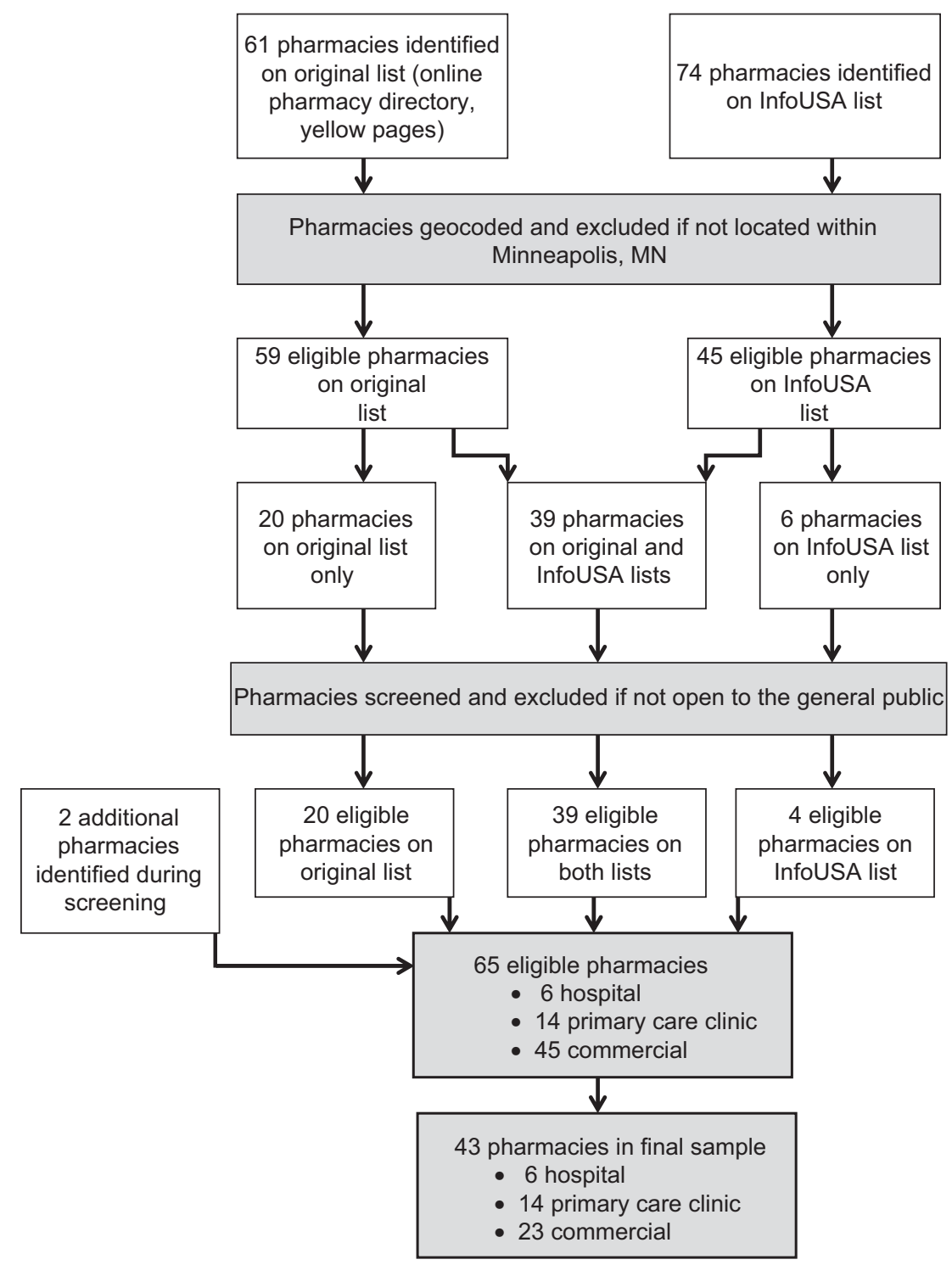

Fig. 1 Flowchart showing pharmacy sample identification, screening and final inclusion

shown in Fig. 1. To be included, the pharmacy had to be located in the city of Minneapolis and available to fulfil prescriptions from the general public. An original list of sixty-one pharmacies located within Minneapolis, MN was compiled using an online pharmacy directory (www. pharmacypages.com), Google Maps and the yellow pages. This list was cross-referenced with a list of seventy-four pharmacies obtained from InfoUSA (www.infousa.com). Pharmacies on the original and InfoUSA lists were combined and geocoded. Duplicates and those not located within the city were removed. Two pharmacies were ineligible because they were not open to the public, resulting in a total of sixtyfive pharmacies. Six pharmacies were classified as hospital pharmacies, fourteen as community clinic pharmacies and forty-five as commercial pharmacies.

All hospital pharmacies ( $n$ 6), all community clinic pharmacies ( $n$ 14) and $50 \%$ of the commercial pharmacies
( $n$ 23) were included in the surveyed sample. Commercial pharmacies were stratified by company (Cub, CVS, Rainbow, Target, Walgreens, or other) and by percentage of African-American residents in the census tract based on 2000 census data ( $<10 \%, 10-19.99 \%, 20-29.99 \%, 30-39.99 \%$, $\geq 50 \%$ ). One pharmacy was randomly selected from each intersection of company and percentage of African-American residents. When no pharmacies were classified at a given intersection, two pharmacies within the same percentage of African-American stratum were randomly selected, regardless of pharmacy company.

\section{Data collection protocol}

Each of the forty-three pharmacies was visited by one of the two trained surveyors. Pharmacies were randomly assigned to surveyors within each pharmacy type. Surveyors visited pharmacies during regular business hours. At each 
pharmacy, the surveyor recorded the pharmacy type, the time of arrival and whether foods/beverages were available within $10 \mathrm{ft}(3.05 \mathrm{~m})$ of the pharmacy register. Ten feet $(3.05 \mathrm{~m})$ was chosen to define a proximal distance to the pharmacy register, where pharmacy customers would be expected to pass to pick up their prescription. A pharmacy employee was interviewed about the pharmacy's food/ beverage regulations and policies. The survey protocol defined the head pharmacist as the target person to interview. If not available, a store manager, pharmacy technician or other pharmacy staff person was interviewed. The surveyor also asked the employee opinion questions regarding the sale of foods/beverages in the pharmacy. If foods/beverages were available within $10 \mathrm{ft}$ $(3.05 \mathrm{~m})$ of the pharmacy register, the surveyor proceeded with the shelf space measurements. If foods/beverages were not available within $10 \mathrm{ft}(3.05 \mathrm{~m})$ of the pharmacy register, no additional data were collected.

\section{Measures}

The survey instrument was developed based on existing instruments used to measure the food environment in retail food outlets ${ }^{(4)}$.

\section{Food/beverage measurements}

Availability of foods/beverages within $10 \mathrm{ft}(3.05 \mathrm{~m})$ of the pharmacy register was assessed with two different measures: the linear shelf space devoted to foods/beverages and the variety of foods/beverages available for purchase. Both measurements were further recorded for foods/ beverages located $\leq 3 \mathrm{ft}(\leq 0.91 \mathrm{~m})$ from the pharmacy register. Linear shelf space and variety were measured within four food/beverage categories including snacks, chips, candy and beverages. Beverages with added sugar, including sugar-sweetened soda, sweetened iced tea and fruit punch, were further classified as sugar-sweetened beverages for variety measurements.

Linear shelf space. Linear shelf space was measured with a flexible tape measure as the distance (inches; centimetres) from the left outer edge of an item within a food/beverage category to the right outer edge of all adjacent items within the same category. If items within the same category were found on multiple shelves or in multiple clusters on the same shelves, the linear shelf spaces for all separate clusters were added together for a total linear shelf space measurement for that category.

Variety. Variety was measured by counting the number of different items of different types available within a given food/beverage category. For example, the snack category included crackers, snack mix and pretzels as food types. An item was considered a particular brand, flavour and size of a food/beverage type. Items of the same type with different brands were counted as two different items. Items of the same type with different flavours were counted as two different items. Items were also characterized by size, with three different size categories: $\leq 2 \mathrm{Oz}$ $(\leq 56 \mathrm{~g}),>2 \mathrm{Oz}(>56 \mathrm{~g})$ and $\leq 6 \mathrm{oz}(\leq 170 \mathrm{~g})$. Items of the same type that fell within different size categories were counted as two different items. Variety was considered the total number of items within the food/beverage category.

\section{Pharmacy food/beverage regulations and policies}

Pharmacy regulations and policies regarding the availability of food and beverages were measured using a series of questions administered verbally in person by the surveyor. Regulation questions queried details about the types of food/beverages that may be sold in the pharmacy and where foods/beverages may be placed. The policy question queried the presence of a formal policy regarding sales of foods and beverages in the pharmacy. Pharmacy employees' opinions about the sale of foods/beverages in the pharmacy were assessed using two statements with five Likert-type categorical responses ranging from 'strongly agree' to 'strongly disagree'.

\section{Inter-rater reliability}

To assess inter-rater reliability, both surveyors independently visited a randomly selected sample ( $n$ 6) of $10 \%$ of pharmacies within each pharmacy type (commercial, $n$ 3; community clinic, $n 2$; hospital, $n 1$ ). For categorical measures, reliability was measured as percentage agreement between surveyors' observations. For the computed dichotomous measure of food/beverage availability within $10 \mathrm{ft}(3.05 \mathrm{~m})$ of the pharmacy register, percentage agreement was 100\%. Reliability comparisons were not conducted for the policy and opinion questions because the two surveyors may have completed the survey with different employees.

\section{Data analysis}

All data analysis was conducted using the STATA statistical software package version 11.1 (StataCorp LP, College Station, TX, USA). Distributions of pharmacy characteristics, including pharmacy type and availability of foods/ beverages $\leq 10 \mathrm{ft}(\leq 3.05 \mathrm{~m})$ and $\leq 3 \mathrm{ft}(\leq 0.91 \mathrm{~m})$ from the pharmacy register, were obtained to provide descriptive data about the sample. The distributions of pharmacy food/beverage regulations and policies and employees' responses to the two opinion questions were also obtained. One-way ANOVA was used to determine if shelf space and variety differed by pharmacy type and the presence of a food policy. Statistical significance was determined in all analyses using an $\alpha$ level of $0 \cdot 05$.

\section{Results}

\section{Pharmacy characteristics}

Eighty-six per cent ( $n$ 37) of the original forty-three pharmacies were surveyed. Two of the original commercial pharmacies, three of the community clinic pharmacies and one hospital pharmacy were not surveyed because they had permanently closed, were relocating or were 
Table 1 Availability of snack foods, candy and beverages in thirty-seven pharmacies in Minneapolis, MN, USA, November 2010-January 2011

Distance from pharmacy register

Foods/beverage available $\leq 10 \mathrm{ft}(\leq 3.05 \mathrm{~m})(\%$ yes) $\quad 59 \cdot 5$

Foods/beverage available $\leq 3 \mathrm{ft}(\leq 0.91 \mathrm{~m})$ (\%yes) $\quad 40.5$

\begin{tabular}{|c|c|c|c|c|c|c|c|c|c|c|}
\hline \multirow[b]{4}{*}{ Pharmacy type } & \multicolumn{10}{|c|}{ Shelf space $(\mathrm{cm})$} \\
\hline & \multicolumn{8}{|c|}{$\leq 10 \mathrm{ft}(\leq 3.05 \mathrm{~m})$ from register } & & \\
\hline & \multicolumn{3}{|c|}{ Foods } & \multicolumn{2}{|c|}{ Beverages } & \multicolumn{3}{|c|}{ Total } & \multicolumn{2}{|c|}{ Near register $\leq 3 \mathrm{ft}(\leq 0.91 \mathrm{~m})$} \\
\hline & Mean & SD & $\%$ & Mean & SD $\%$ & Mean & SD & $\%$ & Mean & SD \\
\hline Commercial $(n 10)$ & $411 \cdot 5$ & $266 \cdot 4$ & $70 \cdot 7$ & $167 \cdot 9$ & $287 \cdot 828 \cdot 8$ & $581 \cdot 7$ & $487 \cdot 9$ & 100 & $231 \cdot 4$ & $218 \cdot 7$ \\
\hline Community clinic ( $n$ 9) & $1730 \cdot 5$ & $1321 \cdot 8$ & $86 \cdot 2$ & $276 \cdot 9$ & $285 \cdot 013 \cdot 7$ & $2007 \cdot 6$ & $1446 \cdot 0$ & 100 & $66 \cdot 3$ & $110 \cdot 5$ \\
\hline Hospital (n 3) & $906 \cdot 3$ & $424 \cdot 2$ & $76 \cdot 5$ & $276 \cdot 1$ & $394.523 \cdot 2$ & $1182 \cdot 1$ & $606 \cdot 6$ & 100 & $75 \cdot 2$ & $130 \cdot 0$ \\
\hline \multirow[t]{3}{*}{ Total $(n 22)$} & $1019 \cdot 6$ & $1051 \cdot 8$ & & $226 \cdot 1$ & $290 \cdot 3$ & $1246 \cdot 9$ & $1179 \cdot 3$ & & $142 \cdot 5$ & $183 \cdot 4$ \\
\hline & \multicolumn{10}{|c|}{ Variety* (count) } \\
\hline & \multicolumn{2}{|c|}{ Packaged snacks } & & \multicolumn{2}{|c|}{ Candy } & \multicolumn{2}{|c|}{ Sugar-sweetened beverages } & & \multicolumn{2}{|c|}{ Total foods/beverages } \\
\hline Pharmacy type & Mean & SD & & Mean & $\overline{S D}$ & Mean & SD & & Mean & SD \\
\hline Commercial $(n 10)$ & $2 \cdot 9$ & $4 \cdot 5$ & & $2 \cdot 7$ & $5 \cdot 3$ & $3 \cdot 1$ & $8 \cdot 1$ & & $8 \cdot 7$ & $10 \cdot 7$ \\
\hline Community clinic $(n 9)$ & $30 \cdot 6$ & $28 \cdot 7$ & & $72 \cdot 7$ & $61 \cdot 6$ & $5 \cdot 4$ & $5 \cdot 8$ & & $108 \cdot 7$ & $87 \cdot 8$ \\
\hline Hospital (n 3) & $12 \cdot 0$ & $12 \cdot 1$ & & $38 \cdot 3$ & $3 \cdot 2$ & $1 \cdot 0$ & $1 \cdot 7$ & & $51 \cdot 3$ & $15 \cdot 0$ \\
\hline Total (n 22) & $15 \cdot 5$ & $22 \cdot 6$ & & $36 \cdot 2$ & $50 \cdot 6$ & $3 \cdot 8$ & $6 \cdot 6$ & & $55 \cdot 4$ & $72 \cdot 6$ \\
\hline
\end{tabular}

*Variety defined as the number of different types of items within each food or beverage category.

not open to the public. Sixty-five per cent of the surveys were conducted with the head pharmacist, $16 \%$ with the store manager, $13 \%$ with a pharmacy technician and 5\% with another pharmacy staff person. In all surveyed pharmacies ( $n$ 37), the surveyors received permission from the interviewed employee to conduct shelf space measurements.

\section{Availability offoods/beverages $\leq 10 f t(\leq 3.05 \mathrm{~m})$ and $\leq 3 f t(\leq 0.91 \mathrm{~m})$ from the register}

Table 1 displays the availability of foods/beverages $\leq 10 \mathrm{ft}$ $(\leq 3.05 \mathrm{~m})$ and $\leq 3 \mathrm{ft}(\leq 0.91 \mathrm{~m})$ from the pharmacy register. Approximately $60 \%(n$ 22) of pharmacies had foods/beverages available $\leq 10 \mathrm{ft}(\leq 3.05 \mathrm{~m})$ of the pharmacy register and $43 \%$ ( $n$ 16) of pharmacies had foods/ beverages available $\leq 3 \mathrm{ft}(\leq 0.91 \mathrm{~m})$ from the pharmacy register. Only pharmacies with foods/beverages available $\leq 10 \mathrm{ft}(\leq 3.05 \mathrm{~m})$ from the pharmacy register were included in shelf space measurements.

\section{Shelf space among pharmacies with food/ beverages available $\leq 10 \mathrm{ft}(\leq 3.05 \mathrm{~m})$ from the pharmacy register}

Table 1 also shows the distributions, including means and standard deviations in centimetres, of total food linear shelf space, total beverage linear shelf space, total food/ beverage linear shelf space and near-register $(\leq 3 \mathrm{ft}$; $\leq 0.91 \mathrm{~m}$ ) linear shelf space among all pharmacies and by pharmacy type. Food linear shelf space differed significantly by pharmacy type $(P=0 \cdot 02)$ and was greatest among community clinic pharmacies and lowest among commercial pharmacies. Total beverage shelf space did not significantly differ by pharmacy type $(P=0 \cdot 70)$. Nearregister $(\leq 3 \mathrm{ft} ; \leq 0.91 \mathrm{~m})$ shelf space did not significantly differ by pharmacy type $(P=0 \cdot 11)$.

\section{Variety offoods/beverages among pharmacies with food/beverages available $\leq 10 \mathrm{ft}(\leq 3.05 \mathrm{~m})$ from the pharmacy register}

The distributions, including means and standard deviations in counts, of the variety of snacks, candy, sugar-sweetened beverages and all foods/sugar-sweetened beverages are displayed in Table 1 . The variety of snacks $(P=0 \cdot 02)$ and candy $(P=0.004)$ differed significantly by pharmacy type and was greatest among community clinic pharmacies and lowest among commercial pharmacies. The variety of sugarsweetened beverages not differ significantly by pharmacy type $(P=0 \cdot 57)$. Total variety of all food and sugar-sweetened beverage items differed significantly by pharmacy type $(P=0 \cdot 006)$ and was greatest among community clinic pharmacies and lowest among commercial pharmacies.

\section{Shelf space and variety by pharmacy type among all pharmacies}

Linear shelf space and variety were also compared among all surveyed pharmacies, including both those with foods/ beverages available $\leq 10 \mathrm{ft}(\leq 3.05 \mathrm{~m})$ from the pharmacy register and those with no foods/beverages available $\leq 10 \mathrm{ft}$ $(\leq 3.05 \mathrm{~m})$ from the pharmacy register. Linear shelf space and variety measurements were recorded as zero for pharmacies with no foods/beverages available $\leq 10 \mathrm{ft}(\leq 3.05 \mathrm{~m})$ from the pharmacy register. Among all surveyed pharmacies, total linear shelf space $(P=0 \cdot 002)$ and total variety of all foods and sugar-sweetened beverages $(P=0 \cdot 0003)$ 
Table 2 Responses of employees to policy and opinion questions in thirty-seven pharmacies in Minneapolis, MN, USA, November 2010-January 2011

\begin{tabular}{|c|c|c|}
\hline & $n$ & $\%$ \\
\hline \multicolumn{3}{|l|}{ Policy questions } \\
\hline \multicolumn{3}{|c|}{ Are there restrictions on the types of foods/beverages that can be sold in the pharmacy? } \\
\hline Any foods/beverages allowed & 18 & $50 \cdot 0$ \\
\hline Only some foods/beverages allowed & 3 & $8 \cdot 3$ \\
\hline No foods/beverages allowed & 2 & $5 \cdot 6$ \\
\hline Don't know/not applicable & 13 & $36 \cdot 1$ \\
\hline \multicolumn{3}{|c|}{ Are there restrictions on where foods/beverages can be placed in the pharmacy? } \\
\hline Yes & 2 & $5 \cdot 6$ \\
\hline No & 21 & $58 \cdot 3$ \\
\hline Don't know/not applicable & 13 & $36 \cdot 1$ \\
\hline \multicolumn{3}{|c|}{ Is there a formal policy about what foods/beverages are allowed to be sold in the pharmacy? } \\
\hline Yes & 6 & $16 \cdot 7$ \\
\hline No & 20 & $55 \cdot 6$ \\
\hline Don't know/not applicable & 10 & $27 \cdot 8$ \\
\hline \multicolumn{3}{|l|}{ Opinion questions } \\
\hline \multicolumn{3}{|c|}{ Pharmacies should make foods and beverages available for sale for their customers } \\
\hline Strongly agree & 8 & $23 \cdot 5$ \\
\hline Agree somewhat & 9 & $26 \cdot 5$ \\
\hline Neither agree/disagree & 9 & $26 \cdot 5$ \\
\hline Disagree somewhat & 6 & $17 \cdot 7$ \\
\hline Strongly disagree & 2 & $5 \cdot 9$ \\
\hline \multicolumn{3}{|c|}{$\begin{array}{l}\text { Pharmacies should not make high-energy/high-fat chips, candy and sweetened beverages } \\
\text { available for sale for their customers }\end{array}$} \\
\hline Strongly agree & 8 & $23 \cdot 5$ \\
\hline Agree somewhat & 9 & $26 \cdot 5$ \\
\hline Neither agree/disagree & 9 & $26 \cdot 5$ \\
\hline Disagree somewhat & 6 & $17 \cdot 7$ \\
\hline Strongly disagree & 2 & $5 \cdot 9$ \\
\hline
\end{tabular}

differed significantly by pharmacy type. Community clinic pharmacies had the greatest linear shelf space and variety, while commercial pharmacies had the lowest linear shelf space and variety. Near-register $(\leq 3 \mathrm{ft}$; $\leq 0.91 \mathrm{~m})$ linear shelf space did not differ significantly by pharmacy type $(P=0.54)$.

\section{Policies regarding the sale of foods/beverages in pharmacies}

Reported food/beverage policies for the pharmacies reported by the interviewed employee ( $n$ 36) are shown in Table 2. For both policy questions, over one-third ( $n$ 13, $36 \cdot 1 \%)$ of pharmacy employees did not know if the pharmacy had any regulations or indicated that the regulation was not applicable because the pharmacy did not sell foods/beverages. Half ( $n$ 18, 50\%) of the pharmacies allowed any foods/beverages to be sold in the pharmacy and just over half of the pharmacies ( $n 21,58 \cdot 3 \%)$ had no restrictions on where foods/beverages can be placed.

The presence of a policy regarding the sale of foods/ beverages in the pharmacy did not differ significantly by pharmacy type $(P=0 \cdot 10)$. Pharmacies with policies were significantly less likely to have food/beverages available within $10 \mathrm{ft}(3.05 \mathrm{~m})$ of the pharmacy register than pharmacies without policies $(P=0 \cdot 03)$. Pharmacies with policies had less shelf space and variety of foods and beverages available than pharmacies without policies, but these associations were not statistically significant (shelf space, $P=0 \cdot 14$; variety, $P=0 \cdot 72$ ).

\section{Opinions regarding the sale of foods/beverages in pharmacies}

Pharmacy employees' responses to the two opinion statements regarding the sale of foods/beverages in the pharmacy area are shown in Table 2. Over half of interviewed employees ( $n$ 34) agreed that pharmacies should make foods and beverages available for sale for their customers and over half agreed that pharmacies should not make high-energy and high-fat snacks, candy and sweetened beverages available for sale for their customers.

\section{Discussion}

In the present study, two-thirds of pharmacies had foods or beverages available within $10 \mathrm{ft}(3.05 \mathrm{~m})$ of the pharmacy register. Pharmacies offered over fifty types of snacks, candy and sugar-sweetened beverages within $3 \mathrm{ft}$ $(0.91 \mathrm{~m})$ of the pharmacy register. This finding is disturbing given the role that pharmacies play in promoting health in the community. The sale of high-energy snack foods and sugar-sweetened beverages works against the mission of a pharmacy and is at odds with its purpose of promoting public health. More surprising was the finding that community-based clinic pharmacies offered even more snack foods and sugar-sweetened beverages than commercial, for profit pharmacies. This finding shows that customers visiting a community clinic pharmacy are more likely to encounter high-energy snack foods and 
sugary beverages on their way to pick up their prescriptions than customers visiting a commercial pharmacy.

Commercial pharmacies might be expected to have the greatest availability of foods and beverages because they are often part of larger retail environments that sell a variety of products. However, the results of the current study indicate that food and beverage availability is highest in the community clinic pharmacies. The reason for this may be that the availability of foods and beverages within $10 \mathrm{ft}(3.05 \mathrm{~m})$ of the pharmacy register is associated with the overall size of the retail area. In pharmacies with smaller retail areas, such as community clinic pharmacies, foods and beverages may be placed within $10 \mathrm{ft}(3.05 \mathrm{~m})$ of the pharmacy register by default because there is no retail space available more than $10 \mathrm{ft}(3.05 \mathrm{~m})$ away from the pharmacy register. In comparison, foods and beverages can be placed more than $10 \mathrm{ft}$ $(3.05 \mathrm{~m})$ from the pharmacy register in pharmacies with larger retail areas. The lower availability of foods and beverages in commercial pharmacies may therefore reflect differences in the sizes of the retail areas in commercial pharmacies compared with community clinic and hospital pharmacies, not necessarily differences in the strategic placement of foods and beverages near the pharmacy register.

The results of the present study also showed that only one-sixth of pharmacies had a policy regarding the availability of foods/beverages in the pharmacy area. The prevalence of a food/beverage policy may be underestimated because only store-level pharmacy staff persons were queried. Ideally, hospital, managed care and corporate administrators responsible for pharmacy food policies should have been surveyed to identify the existence of any food policy that affected the pharmacy. It is unclear at what level these policies are developed. However, at the store level, it is clear that pharmacy managers, technicians and staff have little awareness of such policies if they do exist. The high availability of foods and beverages for sale in pharmacies makes it clear that if such policies exist, they are not being enforced at the store or clinic level. The low prevalence of food/beverage policies is not surprising because prior to the present study, few data documented the availability of snacks, candy and sweetened beverages in pharmacies. There has likely been little pressure from policy makers to develop policies regulating food and beverage availability in the pharmacy environment.

Over half of pharmacy employees agreed that pharmacies should make foods and beverages available for their customers. Similarly, over half of employees agreed that pharmacies should not make high-energy and high-fat snacks, candy and sweetened beverages available for sale for their customers. However, the identical distribution of responses is not attributable to employees answering the same response for both questions.

\section{Study limitations}

The shelf space and variety measurements were conducted only within $10 \mathrm{ft}(3.05 \mathrm{~m})$ of the pharmacy register, which is a potential limitation of the study. Foods and beverages located more than $10 \mathrm{ft}(3.05 \mathrm{~m})$ from the pharmacy register were excluded from shelf space measurements. Therefore, linear shelf space and variety measurements may underestimate the availability of foods and beverages in pharmacies.

The small sample size of five hospital pharmacies is another potential limitation of the study. Of the five hospital pharmacies surveyed, only three had foods or beverages available within $10 \mathrm{ft}(3.05 \mathrm{~m})$ of the pharmacy register. Therefore, the linear shelf space and variety data presented herein may not accurately describe the food and beverage availability in all hospital pharmacies.

Additionally, the availability of foods and beverages in the surveyed pharmacies may not be generalizable to pharmacies located in other states or in non-urban areas. Policies regulating pharmacies and other retail environments may differ by state and pharmacies located in suburban or rural areas may have different space constraints or retail environments from pharmacies located in cities. Data about the food environments in pharmacies located in other states and in urban and rural areas are needed to describe if and how pharmacy food environments differ by state and demographic region.

\section{Study strengtbs}

The present study is the first one to describe the linear shelf space and variety of foods and beverages in pharmacies and to compare the availability of foods and beverages by pharmacy type. Additionally, it is the first study to investigate whether pharmacies have policies regarding the availability of foods and beverages. Few pharmacies have policies regulating the availability of foods and beverages. With the widespread availability of energy-dense foods and beverages in pharmacies and the current obesity epidemic, there is a need for more pharmacies to implement policies regulating the availability of energy-dense foods and beverages.

\section{Conclusions}

Candy, snacks and sugar-sweetened beverages are available for sale in most pharmacy environments, and the largest availability is in community clinic pharmacies. Few pharmacies have policies that regulate the availability and sale of foods and beverages. Policies to limit the sale of energydense foods and sugary beverages in pharmacies are needed.

\section{Acknowledgements}

This research received no specific grant from any funding agency in the public, commercial or not-for-profit sectors. The authors have no conflicts of interest to declare. S.A.F. conceptualized and designed the study, supervised data collection activities and contributed to writing the manuscript. A.W. and A.S. contributed to development of measures and data collection protocols, collected and analysed the data and 
contributed to manuscript writing. J.W. advised on data analysis and contributed to study design and manuscript writing.

\section{References}

1. French SA, Story M \& Jeffery RW (2001) Environmental influences on eating and physical activity. Annu Rev Public Health 22, 309-335.
2. Farley T, Baker E, Futrell L et al. (2007) The ubiquity of energy-dense snack foods: a national multicity study. Am J Public Health 100, 306-311.

3. Hill J \& Peters J (1998) Environmental contributions to the obesity epidemic. Science 280, 1371-1374.

4. French S, Story M, Fulkerson J et al. (2004) An environmental intervention to promote lower fat food choices in secondary schools: outcomes of the TACOS study (Trying Alternative Cafeteria Options in Schools). Am J Public Health 94, 1507-1512. 